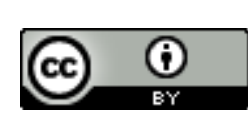

\title{
SER PEDAGOGO: \\ A escolha PROFISSIONAL DE EgRESSOS DO CURSO DE PEDAGOGIA
}

BE PEDAGOGUE:

THE PROFESSIONAL CHOICE OF PEDAGOGY'S COURSES

SER PEDAGOGO:

LA ELECCIÓN PROFESIONAL DE EGRESOS DEL CURSO DE PEDAGOGÍA

\author{
Nilzilene Imaculada Lucindo \\ Célia Maria Fernandes Nunes ${ }^{2}$ \\ Regina Magna Bonifácio de Araújo ${ }^{3}$
}

RESUMO: Este artigo apresenta um recorte da pesquisa "Por onde andam os ex-alunos do curso de Pedagogia/UFOP? Conhecendo a trajetória e o lugar profissional desses egressos" que investigou a função profissional dos concluintes do curso de Pedagogia, formados após a implantação da Resolução $\mathrm{CNE} / \mathrm{CP} \mathrm{n}^{\circ}$ 1/2006. O estudo, de abordagem qualitativa, fez uso da análise documental, da pesquisa bibliográfica e de campo. Na coleta de dados foi utilizado um questionário on-line destinado aos 145 egressos que se formaram entre 2012 e 2015 . Identificamos que $75,7 \%$ dos egressos estão trabalhando; 72,9\% atuam na área educacional; $51,4 \%$ em instituição pública. O fator que mais influenciou a escolha pela Pedagogia foi a identificação com a área e o ambiente educacional. Dos egressos, $70 \%$ se encontram satisfeitos com a profissão e $85,7 \%$ se declararam satisfeitos com sua escolha, contudo, as más condições e a precarização do trabalho docente são os fatores que justificam a insatisfação destacada por alguns.

PALAVRAS-CHAVE: Curso de pedagogia. Egressos. Escolha profissional. Satisfação profissional.

ABSTRACT: This article presents a review of the research "Where are the alumni of the course of Pedagogy/UFOP? Knowing the trajectory and the professional place of these graduates" that investigated the professional function of the graduates of the Pedagogy course, formed after the implementation of Resolution $\mathrm{CNE} / \mathrm{CP} \mathrm{n}^{\mathrm{o}} 1 / 2006$. The research of qualitative approach made use of documentary analysis, bibliographical and field research. In the data collection, an online questionnaire was used for the 145 graduates who graduated between 2012 and 2015. We identified that $75.7 \%$ of the graduates are working; $72.9 \%$ work in the educational area; $51.4 \%$ in a public institution. The factor that most influenced the choice for Pedagogy was the identification with the area and the educational environment. Of the graduates, $70 \%$ are satisfied with the profession and $85.7 \%$ declared themselves satisfied with their choice, however, the poor conditions and the precariousness of the teaching work are the factors that justify the dissatisfaction highlighted by some.

KEYWORDS: Course of pedagogy. Exit. Choose professional. Professional satisfaction.

RESUMEN: Este artículo presenta una revisión de la investigación "¿Dónde está el alumnado del curso de Pedagogy/UFOP? Conozca la trayectoria y el lugar profesional de estos graduados" que investigó la función profesional de los graduados del curso de pedagogía, Resolución CNE/CP n ${ }^{\circ} 1 / 2006$. El estudio, la orientación cualitativa, el uso del documental de análisis, bibliografía y campo de investigación. En la colección de datos, se utilizó un cuestionario en línea para los 145 graduados que se graduaron entre 2012 y 2015. Hemos identificado que el $75.7 \%$ de los graduados están trabajando; $72.9 \%$ work in the education area; $51.4 \%$ in a public institution. El factor que demuestra la elección de Pedagogy se identificó con el área y el entorno de entorno. De los graduados, el $70 \%$ está satisfecho con las profesiones y el $85.7 \%$ declarado ellos mismos con su elección, sin

\footnotetext{
${ }^{1}$ Submetido em: 08/05/2018 - Aceito em: 21/05/2018 - Publicado em: 11/01/2019
}

\begin{tabular}{|c|c|c|c|c|c|c|}
\hline (C) Rev. Educ. Perspec. & Viçosa, $M G$ & v.9 & n. 2 & p.396 & maio/agc & eISSN 2178-8359 \\
\hline
\end{tabular}


embargo, las malas condiciones y la precariedad de la enseñanza de trabajo son los factores que justifican la dissatisfacción resaltada por algún.

PAlabraS Clave: Curso de pedagogía. Los graduados. Elija profesional. Satisfacción profesional.

\section{INTRODUÇÃO}

O curso de Pedagogia tem sido objeto de estudo de diversos autores brasileiros (CRUZ, 2011; LEITE; LIMA, 2010; LIBÂNEO, 2006; 2010a; 2010b; LIBÂNEO; PIMENTA， 2011; LUCINDO, 2015; SAVIANI, 2008). Após a aprovação da Resolução CNE/CP nº 01/2006 (BRASIL, 2006), último marco legal que estabeleceu as diretrizes para esse curso, algumas pesquisas (GATTI; NUNES, 2009; LIBÂNEO, 2010b; PIMENTA, 2014) foram realizadas com o propósito de analisar a formação ofertada aos pedagogos sob a égide dessa Resolução. Esses estudos têm evidenciado as fragilidades e dicotomias presentes na formação dos pedagogos, o que torna indispensável avaliar os impactos desse dispositivo legal na formação dos futuros profissionais de Pedagogia e que, por consequência, também refletirão na sua atuação profissional.

Os dados aqui apresentados representam um recorte da pesquisa intitulada "Por onde andam os ex-alunos do curso de Pedagogia/UFOP? Conhecendo a trajetória e o lugar profissional desses egressos". No seu desenvolvimento foi adotada a abordagem qualitativa (BOGDAN; BIKLEN, 1994). Como procedimentos foram empregados a análise documental, a pesquisa bibliográfica e a pesquisa de campo que tomou como sujeitos os 145 egressos que concluíram o curso de Pedagogia na Universidade Federal de Ouro Preto (UFOP) entre 2012 e 2015. O instrumento utilizado para coletar os dados foi um questionário on-line, desenvolvido no sistema Google Docs, enviado por e-mail. Esse questionário continha questões abertas e fechadas e foi estruturado em quatro categorias: perfil; formação acadêmica; atuação profissional; o curso de Pedagogia e a profissão de pedagogo. Os dados foram coletados em 2016 e tratados pela análise de conteúdo (BARDIN, 2011). Para este texto foram selecionadas todas as questões das categorias 1,2 e 3 e quatro questões da categoria 4 .

Este artigo tem por objetivos caracterizar esses egressos enfocando o seu perfil e a formação acadêmica; averiguar como se deu o processo de inserção no mercado de trabalho; identificar os motivos pelos quais optaram pelo curso de Pedagogia; verificar se os egressos estão satisfeitos com a profissão de pedagogo; apurar o nível de satisfação com a situação profissional; e, averiguar a satisfação com a escolha realizada.

A pesquisa com egressos se configura como uma ação importante no atual cenário brasileiro, à medida que possibilita um maior conhecimento acerca do próprio curso e da entrada dos recém-formados no mundo de trabalho. $\mathrm{O}$ resultado dessas investigações torna-se importante

\begin{tabular}{l|c|c|c|c|c|c|} 
(C) Rev. Educ. Perspec. & Viçosa, $M G$ & v.9 & n.2 & p.396-413 & maio/ago. 2018 & eISSN 2178-8359 \\
\hline
\end{tabular}


para o planejamento, a definição e retroalimentação das políticas educacionais, bem como dos projetos pedagógicos dos cursos de licenciatura. Se tornam ainda imprescindíveis ao sinalizarem novas orientações no que se refere à estrutura e a condução do curso de Pedagogia, mas também podem colaborar para fomentar os debates acerca dos programas e currículos dos cursos de formação de professores, em especial do pedagogo. Especificamente com a instituição investigada, essa pesquisa colaborou para explicitar o perfil de seu alunado e para fornecer informações acerca da satisfação dos egressos com a profissão de pedagogo e com a escolha realizada.

\section{O CURSO DE PEDAGOGIA E A FORMAÇÃO DO PEDAGOGO}

A formação do pedagogo no Brasil, na atualidade, está normatizada pela Resolução do Conselho Nacional de Educação (CNE) no 01/2006 (BRASIL, 2006) que instituiu as Diretrizes Curriculares Nacionais (DCN) para o curso de graduação em Pedagogia, licenciatura, mas quando o curso foi criado pelo Decreto-Lei no 1190 de 04 de abril de 1939 (BRASIL, 1939) seu foco era a formação do Bacharel em Pedagogia para atuar como Técnico/Especialista de Educação e do Licenciado em Pedagogia que atuava como professor no ensino secundário e nas Escolas Normais. Posteriormente, os Pareceres do Conselho Federal de Educação (CFE) no 251/62 (BRASIL, 1963) e no 252/69 (BRASIL, 1969) e a Resolução CNE 01/2006 introduziram alterações no curso.

O Parecer CFE $n^{\circ}$ 251/62 manteve a configuração anterior, modificando apenas o currículo ao estabelecer uma base comum e outra diversificada e a duração do curso que passou para quatro anos, tanto para o bacharelado quanto para a licenciatura. O Parecer CFE no 252/69 reorganizou o curso de Pedagogia e, junto à habilitação já existente de formação de professor para atuar no Ensino Normal, introduziu as habilitações de supervisão, orientação, administração e inspeção escolar, o que na concepção de Libâneo e Pimenta (2011, p. 22), representou uma forma de definir o "exercício profissional do pedagogo não-docente".

A última alteração que se deu a partir da aprovação da Resolução CNE n ${ }^{\circ}$ 1/2006 extinguiu as habilitações, definiu a docência como base de formação do pedagogo e apresentou uma gama de possibilidades de atuação para o Licenciado, uma vez que o curso de Pedagogia se aplica

à formação inicial para o exercício da docência na Educação Infantil e nos anos iniciais do Ensino Fundamental, nos cursos de Ensino Médio de modalidade Normal e em cursos de Educação Profissional, na área de serviços e apoio escolar, bem como em outras áreas nas quais sejam previstos conhecimentos pedagógicos (BRASIL, 2005, p. 6).

A docência apresentada nessa resolução, como mencionam Aguiar et al. (2006), não se refere apenas ao ato de dar aulas. "O sentido da docência é ampliado, uma vez que se articula à idéia

\begin{tabular}{l|c|c|c|c|c|c} 
(C) Rev. Educ. Perspec. & Viçosa, $M G$ & v.9 & n.2 & p.396-413 & maio/ago. 2018 & eISSN 2178-8359 \\
\hline
\end{tabular}


de trabalho pedagógico, a ser desenvolvido em espaços escolares e não-escolares [...]" (AGUIAR et al., 2006, p. 830, grifo do original), entendimento criticado por Libâneo (2006) que discorre acerca das diversas imprecisões conceituais presentes nessa resolução e, inclusive, apresenta uma distinção entre "trabalho pedagógico (atuação profissional em um amplo leque de práticas educativas) e trabalho docente (forma peculiar que o trabalho pedagógico assume na sala de aula)" (LIBÂNEO, 2010a, p. 39).

Ao ser implementada essa diretriz rompeu com o modelo histórico de formação de pedagogos que propiciava a formação do bacharel e licenciado, instituído desde os primórdios do curso e não se ateve às peculiaridades exigidas para a formação do profissional de Pedagogia. De acordo com Leite e Lima (2010), Gatti e Barretto (2009) e Pimenta (2014) com a aprovação das últimas diretrizes essa licenciatura passou a ter amplas atribuições. Pesquisadores (GATTI; NUNES, 2009; LIBÂNEO, 2010b; PIMENTA, 2014) que se dispuseram a analisar a formação oferecida sob a égide da Resolução CNE $n^{0}$ 1/2006 tem evidenciado as dispersões, fragilidades e lacunas presentes na formação dos pedagogos. Constata-se, pela abrangência da formação oferecida, que uma formação tem sido privilegiada em detrimento de outra. Ora é formado o professor das séries (anos) iniciais do Ensino Fundamental, ora o professor de Educação Infantil e ora o gestor. Pimenta (2014) ao analisar os currículos dos cursos de Pedagogia oferecidos por instituições públicas e privadas de São Paulo evidencia como tem se dado essa formação. Segundo a pesquisadora:

\begin{abstract}
as matrizes curriculares dos cursos de Pedagogia refletem os mesmos problemas identificados nas DCNs, ou seja, a indefinição do campo pedagógico, a dispersão do objeto da pedagogia e a redução da pedagogia à docência. Consequentemente, esses cursos, em sua maioria, não estão dando conta de formar, nem o Pedagogo e, tampouco, o professor para os anos iniciais da Educação Básica e para a Educação Infantil (PIMENTA, 2014, p. 17).
\end{abstract}

Esse novo marco regulatório ao enfatizar a formação docente reduz a possibilidade de formar o bacharel. Demonstra ainda ser impossível alcançarmos uma formação abrangente que contemple na sua totalidade a licenciatura e o bacharelado, acabando por descaracterizar o perfil do pedagogo que é ao mesmo tempo um licenciado e bacharel. O pedagogo deve ter a formação de um cientista da educação, com capacidade para atuar na escola, na sala de aula e nos espaços não escolares, mas, competente para compreender o fenômeno educativo na sua totalidade. Esta forma de perceber o Pedagogo se alinha ao pensamento de Libâneo (2010a), Libâneo e Pimenta (2011) e de Saviani (2008), para quem a pedagogia é a ciência da educação, pois tem em sua totalidade como objeto a educação.

Uma legislação mais clara e consistente, em acordo com todas as reais necessidades que a profissão apresenta, que consiga enxergar a especificidade e a complexidade da profissão, associada a uma valorização e reconhecimento mais justo sob o ponto de vista da devida e merecida remuneração, provavelmente alavancaria a educação na sua condição genuína de

\begin{tabular}{l|c|c|c|c|c|c} 
(C) Rev. Educ. Perspec. & Viçosa, $M G$ & v.9 & n.2 & p.396-413 & maio/ago. 2018 & eISSN 2178-8359 \\
\hline
\end{tabular}


formar cidadãos ativos e críticos, bem mais preparados para combater as injustiças e desigualdades existentes na sociedade.

\section{O QUE REVELAM OS DADOS?}

\section{Os egressos do curso de Pedagogia da UFOP: perfil e formação acadêmica}

$\mathrm{Na}$ instituição de ensino superior (IES) pesquisada, 145 alunos concluíram o curso de Pedagogia entre 2012 e 2015. Esse dado demonstra que o número de concluintes é relativamente inferior ao número de ingressantes, já que o percentual de concluintes apurado $(45,3 \%)$ não alcançou $50 \%$ do número de ingressantes. São ofertadas, semestralmente, 40 vagas e, dessa forma, no período mencionado, se todos os ingressantes tivessem concluído o curso, obteríamos um total de 320 egressos ou um número aproximado e não de 145 como foi constatado. Esse é um dado preocupante e aponta para a necessidade de se realizar uma investigação com aqueles que não concluíram o curso, buscando levantar os motivos que levaram esses alunos a abandonarem o mesmo.

Participaram da investigação 70 egressos que compuseram uma amostra que representa 48,2\% do número de concluintes (145). Os egressos do curso de Pedagogia da UFOP se constituem de 94,3\% de mulheres e 5,7\% de homens. As investigações de Jesus (2010), Vargas (2016), Vieira (2010) realizadas com egressos e de Basílio e Machado (2012) e Saraiva e Ferenc (2010) com estudantes do curso de Pedagogia demonstram que as mulheres são a maioria nesse curso. Gatti e Barretto (2009) também registram uma maior presença de mulheres nas licenciaturas, exceto no curso de Licenciatura em Física.

Metade dos egressos é natural da região onde a UFOP está localizada. Dentre os egressos da UFOP, 28,7\% são nascidos em outras localidades do interior de Minas; 7,1\% são naturais da capital desse estado e 7,1\% nasceram em outros estados brasileiros; além do percentual de 7,1\% que não respondeu. Constata-se assim o importante papel de formadora que a UFOP possui ao atender parcela significativa da comunidade onde está inserida.

Em relação à matriz étnica, a composição é a seguinte: $32,9 \%$ de brancos; $22,8 \%$ de negros; $37,1 \%$ de pardos; $4,3 \%$ de amarelos e de $2,9 \%$ de não declarados. A maior parte se declarou branco e pardo, achado similar ao de Senkevics (2017). Entretanto, é relevante destacar o percentual de estudantes que se declararam negros $(22,8 \%)$, o que pode estar associado à política de cotas adotada pela UFOP. Apenas 1,4\% dos egressos, um sujeito em número absoluto, afirmou possuir necessidades especiais. 
Quanto ao estado civil, a maioria, 55,7\%, se declarou solteiro, dado que se aproxima dos encontrados por Sanchez e Gomes (2015) e Gatti e Barretto (2009, p. 161) que revelaram que "pouco mais da metade dos estudantes de Pedagogia são solteiros $(53,9 \%)$ " e difere daqueles encontrados por Vieira (2010) que aponta entre seus entrevistados um percentual maior de egressos casados. Entre os egressos da UFOP também encontramos, 34,3\% de alunos casados; 4,3\% divorciados; 4,3\% com união estável e 1,4\% assinalou a opção “outros”.

No que concerne à formação acadêmica, verificou-se que a maior parte concluiu o Ensino Fundamental $(82,9 \%)$ e Médio $(78,6 \%)$ em escolas públicas. Os estudantes investigados por Gatti e Barretto (2009); Basílio e Machado (2012), em grande parte, são alunos que cursaram o Ensino Médio em escolas públicas. Quanto à modalidade de Ensino Médio, verificamos que 71,4\% dos egressos da UFOP cursaram o Ensino Médio sem habilitação profissional; $24,3 \%$ adquiriram uma habilitação profissional em nível médio, sendo que os demais assinalaram a opção "outros". Resultado similar, em que a maioria dos egressos da Pedagogia concluiu o Ensino Médio sem habilitação profissional, também foi encontrado por Jesus (2010). Esse dado, no entanto, diverge daquele encontrado por Gatti e Barretto (2009) que revelaram que $41,8 \%$ dos alunos da Pedagogia cursaram o Magistério no Ensino Médio. A maioria dos egressos, 74,3\%, concluiu o Ensino Médio entre os anos de 2000 e 2010.

Quanto ao ano de ingresso na UFOP, a percentagem é a seguinte: 34,3\% em 2010; 22,9\% em 2008; $20 \%$ em 2009; 14,3\% em 2011; 5,7\% em 2012 e 2,8\% não informaram o ano. A maior parte dos participantes da pesquisa ingressou $(38,6 \%)$ e concluiu $(72,9 \%)$ o curso de Pedagogia na UFOP quando tinham idade entre 20 e 30 anos.

Gatti e Barretto (2009) consideram como faixa etária ideal para realizar a graduação a idade de 18 a 24 anos. Na investigação desenvolvida por essas autoras, 34,7\% dos alunos pesquisados estão nessa faixa, contudo, registram que "os alunos de Pedagogia são também mais numerosos nas faixas etárias dos mais velhos, no intervalo de 30 a 39 anos, ou acima de 40 anos [...]" (GATTI; BARRETTO, 2009, p. 160). Ao analisarmos a faixa etária dos egressos da UFOP percebemos que se trata de alunos relativamente jovens, todavia, também verificamos que há uma quantidade significativa $(22,8 \%)$ de alunos com idade superior a 40 anos cursando a graduação.

\section{O processo de inserção no mercado de trabalho}

Em relação ao ingresso no mercado de trabalho, averiguamos que 75,7\% dos egressos estão trabalhando, sendo que $72,9 \%$ atuam na área educacional e 4,3\% em outras áreas, dado que demonstra que a área educacional tem sido o principal campo de atuação dos egressos de Pedagogia, o que pode ser explicado pela finalidade do curso de Pedagogia que nasceu em 1939 com o propósito de formar professores. Achado similar foi encontrado por Vargas

\begin{tabular}{l|c|c|c|c|c|c|} 
(C) Rev. Educ. Perspec. & Viçosa, $M G$ & v.9 & n.2 & p.396-413 & maio/ago. 2018 & eISSN 2178-8359 \\
\hline
\end{tabular}


(2016) e Vieira (2010, p. 121) que destacou que "a maioria dos egressos trabalha com educação infantil e anos iniciais do ensino fundamental".

Dentre os que trabalham, 51,4\% atuam em instituição pública e 22,9\% em instituição privada. Quanto às formas de obtenção do emprego; 28,6\% obtiveram por meio de seleção de currículo; $20,0 \%$ por concurso público; $7,1 \%$ por indicação de pessoas influentes e 1,4\% por efetivação de estágio. Obter o emprego por meio de currículo demonstra, além da pouca oferta de concursos públicos para a área, que há uma valorização das experiências e da formação adquirida e que essas podem favorecer a inserção no mercado do trabalho. Desta forma, é importante considerar as experiências formadoras oferecidas durante a graduação e que favorecem o desenvolvimento profissional dos licenciandos.

A maioria, 67,2\%, obteve o emprego com menos de um ano de formado, sendo que 41,4\% ingressaram no mercado enquanto ainda estudavam, dado que demonstra que o mercado de trabalho absorve um número significativo dos profissionais formados pelo curso de Pedagogia, o que pode estar relacionado ao grande número de escolas existentes no país, cerca de 186.000, segundo dados do censo escolar de 2016 (INEP, 2017).

Por que escolheram o curso de Pedagogia?

Gatti et al. (2009, p. 10) ao tratarem da atratividade da carreira docente no Brasil registram que

[...] o projeto profissional é resultado de fatores extrínsecos e intrínsecos, que se combinam e interagem de diferentes formas, ou seja, o jovem, tendo em vista suas circunstâncias de vida, é envolvido por aspectos situacionais e de sua formação, e, outros, como as perspectivas de empregabilidade, renda, taxa de retorno, status associado à carreira ou vocação, bem como identificação, autoconceito, interesses, habilidades, maturidade, valores, traços de personalidade e expectativas com relação ao futuro.

$\mathrm{Na}$ investigação realizada pelos autores, dentre os fatores que mais influenciam os jovens na escolha de uma carreira estão a realização pessoal; a identificação profissional; a remuneração e possibilidade de retorno financeiro; a identificação pessoal; as oportunidades do mercado de trabalho; a concorrência no vestibular e a influência da família e de professores (GATTI et al., 2009).

Dos egressos da UFOP, $58,6 \%$ disseram que no processo seletivo o curso de Pedagogia foi sua primeira opção e 41,4\% escolheram outro curso. Esses dados diferem daqueles apresentados por Basílio e Machado (2012, p. 11) no qual " $59 \%$ dos sujeitos não tiveram o curso de Pedagogia como a primeira opção de curso superior" e dos de Gatti et al. (2009) no qual apenas $2 \%$ indicaram como primeira opção o curso de Pedagogia.

\begin{tabular}{l|c|c|c|c|c|c} 
(C) Rev. Educ. Perspec. & Viçosa, $M G$ & v.9 & n.2 & p.396-413 & maio/ago. 2018 & eISSN 2178-8359 \\
\hline
\end{tabular}


Os dados coletados evidenciaram que são diversos os motivos que conduziram os estudantes da UFOP a optarem pelo curso de Pedagogia, dentre esses estão "a identificação com a área e o ambiente educacional; a influência da família e de amigos; o sonho de ser professor(a); a crença no potencial transformador da educação; a falta de opção; a necessidade de complementar a formação; o incentivo financeiro na carreira; a localização geográfica; o interesse pela área de educação e a facilidade em conseguir um emprego". Alguns desses motivos, como a influência familiar; o desejo de ser professor; já atuar na docência são aspectos comuns aos retratados por Gatti e Barretto (2009) e Lucindo (2015). Outros são similares aos apresentados por Gatti et al. (2009). A influência familiar e de amigos foi um dos aspectos destacados na pesquisa de Saraiva e Ferenc (2010).

Dentre as opções elencadas pelos egressos da UFOP, a mais citada foi a identificação com a área e o ambiente educacional. Os excertos ${ }^{\mathrm{i}}$ abaixo ilustram alguns desses motivos:

Por gostar de Humanas e me identificar com o ambiente escolar desde quando era estudante (P2).

Por não ter condições de morar em outra localidade para fazer o curso que sempre desejei (P6).

Porque meu primeiro emprego foi em um Centro Municipal de Educação Infantil, a minha opção pelo curso de pedagogia foi a partir das vivências enquanto monitora (P24).

Ao concluir o ensino médio não tinha noção de que curso superior fazer. Escolhi Pedagogia seguindo o caminho da minha mãe e adorei o curso (P26).

Porque anteriormente ao curso de Pedagogia já tinha feito magistério e resolvi continuar meus estudos na área da educação. Tive também incentivos de amigos que contribuíram na minha escolha do curso (P47).

Segundo Basílio e Machado (2012, p. 10), "a experiência profissional é um dado significativo no que concerne a escolha do curso". A afirmação das autoras pode justificar o motivo exposto por P24. E os relatos de P26 e P47 ilustram o aspecto apontado por Saraiva e Ferenc (2010).

De acordo com Saraiva e Ferenc (2010, p. 1) "os motivos e as expectativas que determinam o processo de escolha precisam ser considerados, uma vez que são etapas significativas para a formação acadêmica e profissional dos indivíduos" (SARAIVA; FERENC, 2010, p. 1). No estudo desenvolvido é possível perceber que a escolha por uma profissão não é feita aleatoriamente, pois vários fatores exercem influência sobre os sujeitos, dentre esses, encontram-se aqueles alusivos à questão financeira; ao local de residência e sua proximidade com ao do curso; ao mercado de trabalho e inclusive, a falta de opção. O próprio meio em que o sujeito se insere contribui para essa escolha, conforme ressaltam Saraiva e Ferenc (2010).

\begin{tabular}{l|c|c|c|c|c|c|} 
(c) Rev. Educ. Perspec. & Viçosa, $M G$ & v.9 & n.2 & p.396-413 & maio/ago. 2018 & eISSN 2178-8359 \\
\hline
\end{tabular}


Segundo Pedro e Peixoto (2006) justificam a insatisfação profissional o salário do professor; atitude dos pais e da sociedade face aos professores; comportamento/disciplina dos alunos na sala; segurança/estabilidade no trabalho; processos para progressão na carreira. A satisfação profissional é justificada pelo trabalho direto com os alunos; a relação com os alunos; as relações pessoais e profissionais com outros professores (PEDRO; PEIXOTO, 2006).

Do universo pesquisado na UFOP, $70 \%$ disseram estar satisfeitos com essa profissão; 11,4\% assinalaram a opção "em partes", ou seja, que estão parcialmente satisfeitos; 4,3\% relataram que não estão satisfeitos com a profissão. Deixaram de responder a essa questão $10 \%$ dos participantes e 4,3\% informaram que ainda não estão atuando. O número significativo de respostas afirmativas confirma o caminho profissional escolhido por esses egressos, desde a escolha do curso até o momento atual.

Dentre aqueles que se disseram satisfeitos com a profissão, é possível observar que essa satisfação está relacionada "à realização profissional; ao amor a profissão e por gostar do que faz; ao trabalho com crianças; por contribuir com a formação do outro; à autonomia, ao trabalho de equipe e em função dos resultados alcançados; ao campo de atuação ser amplo; pelo fato de a educação ser uma base para evolução do mundo; por gostar de lecionar; por perceber o retorno dos alunos; em função do ambiente de trabalho". Os fatores "realização profissional" e "amor a profissão, gostar do que faz" foram os mais ressaltados pelos egressos.

Bastante satisfeita com a minha profissão pois trabalho em um ambiente onde tenho autonomia para desenvolver meus projetos, trabalho em equipe e tenho grandes resultados $(\mathrm{P} 02)$.

Sim. Apesar de tantos desafios que encontramos, nossa profissão é a base para o progresso do mundo (P57).

É relevante registrar que embora $70 \%$ dos egressos apresentem satisfação com a profissão que escolheram, nos relatos, eles não deixam de evidenciar os desafios presentes nessa área e as condições de trabalho a que estão subjugados, como a desvalorização dos profissionais da educação, a falta de reconhecimento pelo trabalho, a baixa remuneração, a inexistência de planos de carreira e outros fatores que assolam o trabalho docente e contribuem para sua precarização, como já foi abordado por Gatti e Barretto (2009).

Os egressos que demonstraram insatisfação com a profissão de pedagogo, justificaram suas respostas em função da remuneração e do interesse em prosseguir em outra área.

Com o curso sim, mas não pretendo seguir na área. Talvez possa aliá-la à outra, mas ainda é incerto (P10).

\begin{tabular}{|c|c|c|c|c|c|c|}
\hline (C) Rev. Educ. Perspec. & Viçosa, $M G$ & v.9 & $\mathrm{n} .2$ & p.396-413 & maio/ago. 2018 & eISSN 2178-8359 \\
\hline
\end{tabular}


Não. A remuneração não é o que eu esperava (P16).

No estudo de Gatti et al. (2009), o salário foi o segundo fator mais indicado pelos estudantes para não escolher o magistério. De acordo com os autores, a visão que os sujeitos da pesquisa detêm dos docentes e de sua atividade profissional é que os professores são desvalorizados e essa desvalorização tem relação direta com os baixos salários e a carga horária de trabalho excessiva.

Dentre aqueles que assinalaram a opção "em partes", constata-se que a satisfação não é completa, principalmente, devido às más condições de trabalho, aos baixos salários, falta de infraestrutura e recursos, enfim, em virtude da falta de prestígio do setor educacional, como pode ser observado no excerto abaixo.

\begin{abstract}
Atuar como professora é algo muito desafiador. Direcionar, acompanhar o desenvolvimento e aprendizado dos meus alunos é realmente gratificante. [...] Porém, infelizmente, a desvalorização profissional refletida não só no salário baixo, mas também medidas tomadas dentro do ambiente escolar, que desconsideram a realidade da sala de aula; salas de aula pequenas com um número alto de alunos, pouca ventilação me faz repensar se devo continuar atuando como professora (P56).
\end{abstract}

Nível de satisfação com a situação profissional: aspectos financeiro e social

Os gráficos 1 e 2 ilustram a satisfação dos egressos com a profissão em relação aos aspectos financeiro e social. Os dados aqui apresentados podem reiterar a resposta dada à questão anterior, na qual alguns egressos justificaram os fatores que geram insatisfação com a profissão. 




Gráfico 1. Nível de satisfação com a situação profissional - aspecto financeiro Fonte: Elaboração própria a partir do questionário aplicado

Algumas investigações têm demonstrado que a falta de satisfação com a profissão decorre das condições sociopolíticas de trabalho (PEDRO; PEIXOTO, 2006). Reconhece-se que dentre os fatores que respondem pela não satisfação encontram-se a falta de apoio da instituição em que atuam, a baixa remuneração, o pouco reconhecimento social e o excessivo trabalho administrativo. Na pesquisa realizada na UFOP, os dados revelaram que a maioria, $64,3 \%$, tem um nível médio de satisfação com a remuneração financeira e $21,4 \%$ se encontram insatisfeitos.

Ao tratarem da carreira e do salário de docentes da Educação Básica, Gatti e Barretto (2009, p. 239), destacam que o "equacionamento - uma carreira condizente com a sua relevância social, com salários atraentes - ainda não está bem realizado". Essas autoras registram que a remuneração de professores no Brasil é muito desigual, inclusive entre os níveis de ensino e alertam para o fato de que carreiras com salários pouco atrativos não se tornam procuradas pelas novas gerações. "Sendo assim, não é de estranhar que as licenciaturas sejam a escolha de um número cada vez menor de estudantes que ingressam a cada ano no ensino superior brasileiro" (VARGAS, 2016, p. 108).

Em se tratando dos aspectos sociais relacionados à profissão, o gráfico 02 registra números muito próximos aos da situação financeira. Cerca de $62,9 \%$ dos respondentes manifestaram uma satisfação média e apenas $27,1 \%$ relataram um alto nível de satisfação com a profissão.

\begin{tabular}{l|c|c|c|c|c|c} 
(C) Rev. Educ. Perspec. & Viçosa, $M G$ & v.9 & n.2 & p.396-413 & maio/ago. 2018 & eISSN 2178-8359 \\
\hline
\end{tabular}




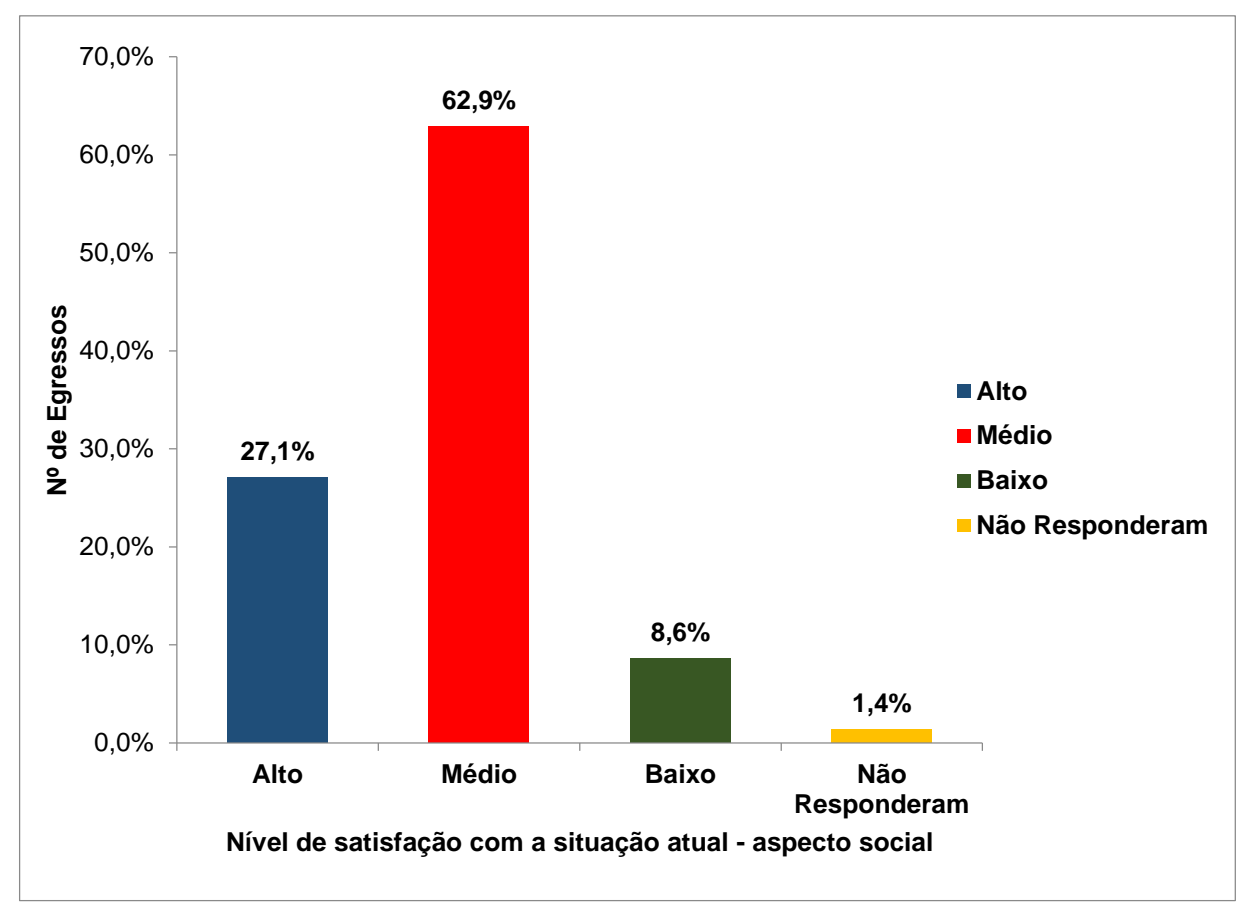

Gráfico 2. Nível de satisfação com a situação profissional - aspecto social Fonte: Elaboração própria a partir do questionário aplicado.

Esses dados revelam que nas dimensões financeiras e sociais não existem diferenças significativas entre os egressos, e embora eles evidenciem um nível alto de satisfação com a profissão, ao se tratar dos aspectos financeiros e sociais da mesma, isto não se confirma. Conforme conclui Vargas (2016, p. 102),

[...] as licenciaturas, locus da formação de profissionais da educação, ocupam posição periférica na hierarquia de cursos e carreiras do sistema de ensino superior brasileiro, dispondo de escasso prestígio social, não obstante o discurso de que a educação é fundamental para o país e de que os professores deveriam ser valorizados.

Em relação às condições sociais e financeiras da profissão, a investigação de Gatti et al. (2009, p. 51) salienta que

[...] os estudantes atribuem às condições financeiras e sociais da profissão docente a recusa em ser professor. Entre as principais idéias discutidas, é patente a concepção de que esse profissional é, em geral, mal remunerado e desprestigiado, e daí advém boa parte dos problemas enfrentados na contemporaneidade pela profissão, como a insatisfação dos que já estão inseridos no campo da docência e a rejeição daqueles que ainda estão na iminência de se inserir no mercado de trabalho.

Como apontam Pedro e Peixoto (2006, p. 257) é relevante estar atento para "as conseqüências [sic] nefastas que os baixos índices de satisfação encontrados junto dos docentes acarretam”.

\begin{tabular}{l|c|c|c|c|c|c} 
() Rev. Educ. Perspec. & Viçosa, $M G$ & v.9 & n.2 & p.396-413 & maio/ago. 2018 & eISSN 2178-8359 \\
\hline
\end{tabular}




\section{A satisfação com a escolha realizada}

Em relação à satisfação com a escolha realizada, 85,7\% dos egressos se declararam satisfeitos por escolher esta profissão; 1,4\% "em partes"; 4,3\% não estão satisfeitos; $1,4 \%$ ainda não atuam e 7,2\% não responderam. Segundo os egressos que responderam afirmativamente, a satisfação com a escolha realizada é justificada "por se sentirem realizados profissionalmente; pelo amor a profissão, por gostar da área de educação; pela amplitude do campo de atuação; pelo aprendizado e crescimento que proporcionou; por permitir refletir sobre questões sociais e mais amplas; por terem uma base para compreender melhor o desenvolvimento infantil; pelo exercício da docência; por trabalhar com crianças; pela possibilidade de transformação". Dentre essas respostas, a mais frequente foi "por se sentirem realizados profissionalmente". Gatti et al. (2009) apontaram este aspecto como sendo um dos fatores que mais influencia os jovens na escolha de uma carreira.

Os depoimentos que seguem demonstram a satisfação dos egressos com a escolha realizada:

\footnotetext{
Sim estou satisfeito por escolher esta profissão e escolheria o curso de Pedagogia novamente, pois no começo da minha formação gostei desta área, e hoje me sinto realizada com a profissão $(\mathrm{P} 13)$.
}

Sim, escolheria o mesmo curso. Pois a minha formação foi muito significativa e eu me encontrei estudando mais sobre a Educação e mais especificamente sobre a Educação de Jovens e Adultos (P22).

O estudo de Lucindo (2015) realizado com pedagogos que atuam na coordenação pedagógica de instituições de ensino público localizadas na mesma região em que a UFOP está inserida demonstrou que os pedagogos estão satisfeitos com sua escolha profissional, sendo que 93,3\% dos sujeitos entrevistados optariam novamente pelo curso de Pedagogia e pela profissão de pedagogo, achado similar ao da pesquisa de Jesus (2010).

Dentre os $4,3 \%$, dos egressos que responderam negativamente a essa questão, verificou-se que eles possuem interesse em atuar em outra área ou a insatisfação se dá em virtude da sobrecarga de trabalho, como é apontado pelo egresso P16, o qual relatou "Não, não. Desde que assumi a sala de aula nunca mais tive vida, vivo para a escola e meus alunos. Eu saio da escola mais [sic] a escola não sai de mim". "A exigência excessiva de envolvimento pessoal no trabalho, entendido como desgastante" também foi um aspecto evidenciado dentre os sujeitos participantes da investigação de Gatti et al. (2009, p. 46).

\section{ALGUMAS CONSIDERAÇÕES}

A investigação realizada identificou quem são os egressos do curso de Pedagogia da UFOP e permitiu caracterizar o perfil desses sujeitos, os aspectos relativos a sua formação acadêmica

\begin{tabular}{l|c|c|c|c|c|c|} 
() Rev. Educ. Perspec. & Viçosa, $M G$ & v.9 & n.2 & p.396-413 & maio/ago. 2018 & eISSN 2178-8359 \\
\hline
\end{tabular}


e ao processo de inserção no mercado de trabalho, bem como desvelou os motivos que os conduziram a ingressar no curso, apurando sua satisfação em relação à profissão e à escolha realizada.

O primeiro achado desse estudo diz respeito à evasão no curso de Pedagogia, já que apenas $45,3 \%$ dos ingressantes concluíram o curso, embora somente 58,6\% afirmaram que o curso de Pedagogia foi sua primeira opção. Esse dado pode justificar a evasão, já que o percentual restante, $41,4 \%$, apresentava interesse em realizar um curso distinto da Pedagogia.

Identificou-se que os egressos do curso de Pedagogia da UFOP se constituem, em sua maioria, por mulheres, naturais da região onde a IES investigada está inserida, se sobressaindo aquelas de cor branca e parda, solteiras. Esses egressos, em sua maioria, são oriundos de escolas públicas e concluíram o Ensino Médio sem habilitação profissional entre os anos de 2000 a 2010. Trata-se de alunos que ingressaram na universidade e concluíram a graduação entre os 20 e 30 anos.

Em relação às escolhas dos egressos pelo curso de Pedagogia, a investigação revelou que foram vários os fatores que influenciaram a escolha por essa profissão, se sobressaindo a identificação com a área e o ambiente educacional. Entre os sujeitos pesquisados, $70 \%$ se encontram satisfeitos com a profissão, sendo que essa satisfação tem estreita relação com a "realização profissional" e ao "amor pela profissão". Da mesma forma, 85,7\% se declararam satisfeitos com sua escolha, contudo, mesmos aqueles que estão satisfeitos não deixam de explicitar os desafios implícitos na profissão. Aqueles egressos que demonstraram insatisfação com a profissão de pedagogo, a causa está relacionada à remuneração e ao interesse em prosseguir em outra área. E são justamente as más condições e a precarização do trabalho docente que justificam a insatisfação destacada por alguns egressos.

Os dados levantados permitem concluir que a satisfação com a profissão tem relação com a realização pessoal e profissional. Da mesma forma, a insatisfação perpassa aspectos como a baixa remuneração e a desvalorização ou falta de reconhecimento social que envolve a profissão docente, principalmente, no contexto brasileiro. Aspectos que já foram abordados nos estudos de Pedro e Peixoto (2006) e Gatti et al. (2009) e que demandam intervenção com vistas a reverter o cenário apresentado, pois se não houver valorização da profissão docente, dificilmente, poderemos contar, no futuro, com o trabalho desse profissional.

Acredita-se que os achados dessa pesquisa podem contribuir com o campo dos estudos na área da Pedagogia e da formação de professores, bem como para refletir sobre as condições de trabalho a que estão subjugados os profissionais que atuam na educação brasileira. 


\section{REFERÊNCIAS}

AGUIAR, Márcia Ângela da Silva et al. Diretrizes curriculares do curso de pedagogia no Brasil: disputas de projetos no campo da formação profissional da educação. Educação \& Sociedade, Campinas, v. 27, n. 96 - Especial, p. 819-842, out. 2006. Disponível em: http://www.scielo.br/pdf/es/v27n96/a10v2796.pdf Acesso em: 13 out. 2011.

BARDIN, Laurence. Análise de conteúdo. São Paulo: Edições 70, 2011.

BASÍLIO, Márcia Alves Tenório; MACHADO, Laêda Bezerra. A escolha por pedagogia - o que revelam os estudantes. Encontro de Pesquisa Educacional em Pernambuco, IV, Caruaru, 2012. Disponível em: http://www.epepe.com.br/EPEPE2012_IV/Trabalhos/04/C04/C4-81.pdf Acesso em: 07 jul. 2015.

BOGDAN, Robert; BIKLEN, Sari. Investigação qualitativa em educação- uma introdução à teoria e aos métodos. Porto: Porto Editora, 1994.

BRASIL. Conselho Federal de Educação. Parecer n ${ }^{\circ}$ 251/62. Fixa o currículo mínimo e a duração do Curso de Pedagogia. Relator: Valnir Chagas. Documenta. nº 11, jan./fev. 1963. 59-66p.

BRASIL. Conselho Federal de Educação. Parecer n 252/69. Fixa os mínimos de conteúdo e duração a serem observados na organização do curso de Pedagogia. Relator: Valnir Chagas. Documenta. $\mathrm{n}^{\circ}$ 100, abr. 1969. 101-139p.

BRASIL. Conselho Nacional de Educação. Parecer CNE/CP n ${ }^{\circ}$ 05/2005 de 13 de dezembro de 2005. Diretrizes Curriculares Nacionais para o Curso de Pedagogia. Diário Oficial da União, Brasília, 15 maio 2006. Disponível em: http://portal.mec.gov.br/cne/arquivos/pdf/pcp05_05.pdf Acesso em: 26 dez. 2013.

BRASIL. Conselho Nacional de Educação. Resolução nº 1/2006 de 15 de maio de 2006. Institui Diretrizes Curriculares Nacionais para o Curso de Graduação em Pedagogia, licenciatura. Diário Oficial da União, Brasília, 16 maio 2006, Seção 1, p. 11. Disponível em: http://portal.mec.gov.br/cne/arquivos/pdf/rcp01_06.pdf Acesso em: $21 \mathrm{dez} .2013$.

BRASIL. Decreto-Lei no 1190 de 04 de abril de 1939. Dá organização à Faculdade Nacional de Filosofia. Diário Oficial da União, Rio de Janeiro, RJ, 06 abr. 1939. Disponível em: http://www2.camara.leg.br/legin/fed/declei/1930-1939/decreto-lei-1190-4-abril-1939349241-publicacaooriginal-1-pe.html Acesso em: 08 set. 2013.

CRUZ, Giseli Barreto da. Curso de Pedagogia no Brasil: história e formação com pedagogos primordiais. Rio de Janeiro: Wak Editora, 2011. 
GATTI, Bernardete Angelina; et al. A atratividade da carreira docente no Brasil.

Relatório Final. São Paulo: Fundação Carlos Chagas; Fundação Vitor Civita, 2009.

Disponível em: http://www.zerohora.com.br/pdf/15141177.pdf Acesso em: 03 abr. 2018.

GATTI, Bernardete Angelina (Coord.); BARRETTO, Elba Siqueira de Sá. Professores do

Brasil: impasses e desafios. Brasília: UNESCO, 2009. Disponível em:

http://unesdoc.unesco.org/images/0018/001846/184682por.pdf Acesso em: 07 jun. 2013.

GATTI, Bernardete Angelina; NUNES, Marina Muniz Rossa (Orgs.). Formação de professores para o Ensino Fundamental: estudo de currículos das licenciaturas em Pedagogia, Língua Portuguesa, Matemática e Ciências Biológicas. São Paulo: Fundação Carlos Chagas, DPE, 2009. Disponível em: https://goo.gl/piYfGV Acesso em: 05 jan. 2017.

INEP. INSTITUTO NACIONAL DE ESTUDOS E PESQUISAS EDUCACIONAIS ANÍSIO TEIXEIRA. Censo da educação básica: 2016 - notas estatísticas. - Brasília: Instituto Nacional de Estudos e Pesquisas Educacionais Anísio Teixeira, 2017. 29 p. Disponível em: http://download.inep.gov.br/educacao_basica/censo_escolar/notas_estatisticas/2017/notas_est atisticas_censo_escolar_da_educacao_basica_2016.pdf Acesso em: 23 abr. 2017.

JESUS, Simone Penteado Silva de. A formação do pedagogo: estudo de caso com alunos egressos de um curso de pedagogia. 2010. 125f. Dissertação (Mestrado em Educação) Universidade Metodista de São Paulo, São Bernardo do Campo, 2010. Disponível em: http://tede.metodista.br/jspui/handle/tede/1164 Acesso em: 15 fev. 2017.

LEITE, Yoshie Ussami Ferrari; LIMA, Vanda Moreira Machado. Cursos de Pedagogia no Brasil: o que dizem os dados do INEP/MEC? Ensino Em-Revista, Uberlândia, v. 17, n. 1, p. 69-93, jan./jun. 2010. Disponível em:

http://www.seer.ufu.br/index.php/emrevista/article/view/8185/5197 Acesso em: 03 mar. 2015.

LIBÂNEO, José Carlos. Diretrizes Curriculares da Pedagogia: imprecisões teóricas e concepção estreita da formação profissional de educadores. Educação e Sociedade. Campinas: Editora da UFPR, v. 27, n. 96 - Especial, p. 843-876, 2006. Disponível em: http://www.scielo.br/pdf/es/v27n96/a11v2796.pdf Acesso em: 14 jan. 2016.

LIBÂNEO, José Carlos.O ensino da Didática, das metodologias específicas e dos conteúdos específicos do ensino fundamental nos currículos dos cursos de Pedagogia. Revista

Brasileira de Estudos Pedagógicos, Brasília, v. 91, n. 229, p. 562-583, set./dez. 2010b. Disponível em: http://rbep.inep.gov.br/index.php/rbep/article/view/630 Acesso em: 23 abr. 2017.

LIBÂNEO, José Carlos. Pedagogia e pedagogos, para que?12. ed. São Paulo: Cortez, 2010a.

\begin{tabular}{l|c|c|c|c|c|c} 
(c) Rev. Educ. Perspec. & Viçosa, $M G$ & v.9 & n.2 & p.396-413 & maio/ago. 2018 & eISSN 2178-8359 \\
\hline
\end{tabular}


LIBÂNEO, José Carlos; PIMENTA, Selma Garrido. Formação de profissionais da educação: visão crítica e perspectiva de mudança. In: PIMENTA, Selma Garrido (Org.) Pedagogia e Pedagogos:caminhos e perspectivas. 3. ed. São Paulo: Cortez, 2011. p. 15-61.

LUCINDO, Nilzilene Imaculada. Quem são os pedagogos que atuam nas instituições de ensino público da SRE-OP: um estudo sobre o perfil, a formação e a trajetória desses profissionais. 2015. 158f. Dissertação (Mestrado em Educação) - Universidade Federal de Ouro Preto, 2015. Disponível em: http://www.repositorio.ufop.br/handle/123456789/5671 Acesso em: 18 jun. 2016.

PEDRO, Neuza; PEIXOTO, Francisco. A satisfação profissional e auto-estima dos professores. Análise Psicológica, v. 24, n. 2, p. 247-262, 2006.

PIMENTA, Selma Garrido. A formação de professores para a Educação Infantil e para os anos iniciais do Ensino Fundamental: análise do currículo dos cursos de Pedagogia de instituições públicas e privadas do Estado de São Paulo. Encontro Nacional de Didática e Prática de Ensino, XVII, 2014, Fortaleza. Disponível em:

http://www.uece.br/eventos/xviiendipe/ Acesso em: 24 jan. 2015.

SANCHEZ, Liliane Barreira; GOMES, Rafael Madureira. Quem são os alunos do curso de Pedagogia e porque escolhem essa profissão: um estudo de caso. EDUCERE Congresso Nacional de Educação, XII, 2015, Curitiba. Disponível em:

http://educere.bruc.com.br/arquivo/pdf2015/17538_8109.pdf. Acesso em: 03 abr. 2018.

SARAIVA, Ana Cláudia Lopes Chequer; FERENC, Alvanize Valente Fernandes. A escolha profissional do curso de pedagogia: análise das representações sociais de discentes. Reunião Nacional da Associação Nacional de Pós-Graduação e Pesquisa em Educação, XXXIII, 2010, Caxambu. Disponível em:

<http://33reuniao.anped.org.br/33encontro/app/webroot/files/file/Trabalhos\%20em\%20PDF/ GT08-6350--Int.pdf>. Acesso em: 08 jul. 2015.

SAVIANI, Dermeval. A pedagogia no Brasil: história e teoria. Campinas: Autores Associados, 2008.

SENKEVICS, Adriano Souza. Cor ou raça nas instituições federais de ensino superior: explorando propostas para o monitoramento da Lei de Cotas. Brasília: Instituto Nacional de Estudos e Pesquisas Educacionais Anísio Teixeira, 2017. Disponível em:

http://portal.inep.gov.br/informacao-da-publicacao/-/asset_publisher/6JYIsGMAMkW1/do cument/id/689605. Acesso em: 30 abr. 2017.

VARGAS, Michely de Lima Ferreira. Formação e inserção profissional do pedagogo: o panorama histórico desta carreira e os egressos do curso de Pedagogia presencial da Faculdade de Educação da UFMG. 2016. 297 f. Tese (Doutorado em Educação) Universidade Federal de Minas Gerais, Belo Horizonte. 2016. Disponível em: http://www.bibliotecadigital.ufmg.br/dspace/handle/1843/BUBD-AA2H3A. Acesso em: 15 fev. 2017.

\begin{tabular}{l|c|c|c|c|c|c} 
(C) Rev. Educ. Perspec. & Viçosa, $M G$ & v.9 & n.2 & p.396-413 & maio/ago. 2018 & eISSN 2178-8359 \\
\hline
\end{tabular}


VIEIRA, Josimar de Aparecido. Qualidade da formação inicial de pedagogos: indicadores na visão de egressos. 2010. 212 f. Tese (Doutorado em Educação) - Pontifícia Universidade Católica do Rio Grande do Sul, Porto Alegre. 2010. Disponível em: http://repositorio.pucrs.br/dspace/bitstream/10923/2803/1/000430601-Texto\%2BCompleto0.pdf. Acesso em: 14 abr. 2017.

\section{NOTAS}

${ }^{\mathrm{i}}$ Os participantes da pesquisa foram identificados por um P (Pedagogo) e um numeral visando preservar sua identidade.

\section{SOBRE OS AUTORES}

${ }^{1}$ Nilzilene Imaculada Lucindo - Mestra em Educação pela UFOP. Professora do Departamento de Administração Educacional da Faculdade de Educação da UEMG. E-mail:

nilzilenelucindo@yahoo.com.br - ORCID: http://orcid.org/0000-0003-2766-8951

${ }^{2}$ Célia Maria Fernandes Nunes - Doutora em Educação. Professora do curso de Pedagogia e do Programa de Mestrado em Educação da Universidade Federal de Ouro Preto. E-mail: cmfnunes1@gmail.com - ORCID: http://orcid.org/0000-0002-2338-1876

${ }^{3}$ Regina Magna Bonifácio de Araújo - Doutora em Educação. Professora do curso de Pedagogia e do Programa de Mestrado em Educação da Universidade Federal de Ouro Preto. E-mail: regina.magna@hotmail.com - ORCID: http://orcid.org/0000-0002-1443-4876 